Brzezińska Agnieszka, Borowiecka Monika, Zając Marlena, Warchol Konrad, Michniak Wiktor. ADHD in women - a review. Journal of Education, Health and Sport. 2021;11(9):491-496. eISSN 2391-8306. DOI http://dx.doi.org/10.12775/JEHS.2021.11.09.063 https://apcz.umk.pl/JEHS/article/view/JEHS.2021.11.09.063

https://zenodo.org/record/5524342

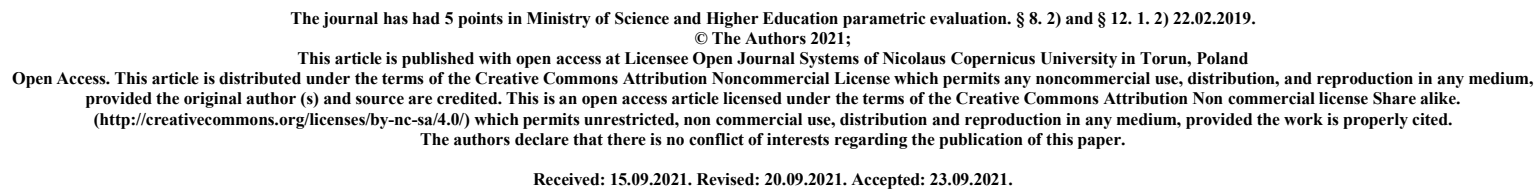

\title{
ADHD in women - a review
}

Agnieszka Brzezińska (1); brzezinska2agnieszka@gmail.com; https://orcid.org/0000-0001-5730-8813

Monika Borowiecka (1); monnikaborowiecka@gmail.com; https://orcid.org/0000-0003-2612-7838

Marlena Zając (1); marlenzajac11@gmail.com; https://orcid.org/0000-0002-6251-0175

Konrad Warchol (1); konrad.wrh@gmail.com; https://orcid.org/0000-0001-9467-680X

Wiktor Michniak (2); wiktor.michniak97@gmail.com https://orcid.org/0000-0002-7079-813X

(1) Faculty of Medicine, Medical University of Lublin, Aleje Racławickie 1, 20-059 Lublin, Poland

(2) Faculty of Medicine, Medical University of Silesia, Poniatowskiego 15, 40-055 Katowice, Poland

\begin{abstract}
Introduction: Attention-deficit hyperactivity disorder (ADHD) for many years has been thought to occur mainly in the male population. However, recent studies and change in professionals' perception allowed us to understand that there are significant differences between predominant features related to the gender of the affected person, which changes our look at how the condition may exhibit in women.

Current state of knowledge: In this review, we provide a general look at the disorder, its characteristics in the young and adult population, differences in symptoms and finally - how it may prove difficult to diagnose this condition among women. Several factors that could contribute to development of ADHD were listed in literature, among them genetics, prenatal period, diet and parents' emotional wellbeing. Concerning women, they are considered to
\end{abstract}


internalize their psychological struggles, such as depression and stress more often than men, rendering them more susceptible toward suicidal behaviors and making diagnosis harder.

Conclusions: When it comes to diagnosis in women, the main difficulty is that the symptoms are presented in a different way compared to men suffering from the same disorder. Because of those reasons, it's harder to make a proper diagnosis. Therefore, further studies, taking account of affected one's gender needs to be conducted, while medical professionals have to be more cautious.

Key words: ADHD, women, adults, diagnosis

\section{Introduction and purpose}

Attention-deficit and hyperactivity disorder (ADHD) was first described in 1798 by Scottish physician Sir Alexander Crichton. He noticed that some people have more difficulties focusing on their activities than others. His observations were consistent with modern descriptions of ADHD in DSM-IV [3]. It is the most common neurodevelopmental disease in childhood, affecting millions of children every year. According to a survey from 2016, over 6.1 million children aged 4-17 had ADHD and boys were more likely to be diagnosed with it compared to girls (12.9\% to 5.6\%). Moreover, 6 in 10 children with ADHD have at least one more mental, emotional or behavioral disorder. Therefore, it is not uncommon that ADHD comes with other comorbidities such as anxiety (33\%), depression (17\%), autism spectrum disorder $(14 \%)$ or even Tourette syndrome $(1 \%)$ which in some cases makes it difficult to give a proper diagnosis [2]. The risk factors include: low birth weight or premature birth; brain damage during pregnancy or later in life, and also epilepsy. ADHD tends to run into families, therefore genetics play a crucial role in inheriting that disease [6]. Moreover, there is some evidence showing that maternal thyroid dysfunction puts children at risk to develop this disease $[7,8]$. ADHD was once thought to be a predominantly male disorder. However, recent studies show subtle, but significant differences in the symptom profile, which indicates the importance of proper diagnosis of women with ADHD who can be unrecognized for many years leading them to struggle with more severe symptoms later in life $[9,10]$.

This review analyzed the available studies using the "PubMed" database, and the search criteria used the search term "ADHD in women". The work focuses on gender differences in ADHD and difficulties with the diagnosis in women. The aim of the work is to assess the importance of implications of these differences.

\section{The state of knowledge}

\section{ADHD in adults}

It is thought that in order to be diagnosed with $\mathrm{ADHD}$, behavior of the patient must fall into two of the following categories: inattentiveness and hyperactivity or impulsiveness. However, it is not always the case and patients can present only symptoms out of one category. For example, there can be inattentiveness without hyperactivity and vice versa. A disorder, first diagnosed in childhood, often continues into adulthood with persistent symptoms which can lessen with age, especially hyperactivity while the inattentiveness gets worse because of the pressure of adult life [4,5]. It is believed that ADHD cannot develop in adults for the first time 
therefore in order for it to be diagnosed, the symptoms have to be present in childhood [11]. Klassen et al. conducted a study which included 335 children where they used a health-related quality of life questionnaire (HRQL) and came to the conclusion that ADHD had a significant impact on multiple domains of HQRL. Moreover, in comparison to normative data, children with ADHD had more parent - related problems. Parents' emotional wellbeing, as well as their time to meet their own needs were also significantly affected [12]. Environmental factors can also have an impact on the course of the disease. There is some evidence that insufficient diet and chronic deficiencies of iron, zinc and magnesium can deepen symptoms of ADHD in children and the intake of low glycemic food can help to reduce the symptoms as well as polyunsaturated fatty acids $[14,17]$. Beyens et al. made a review that contained forty years of research showing that there is correlation between children's media use and ADHD- related symptoms [15]. In the time of the COVID pandemic, patients with ADHD had experienced worsening of their wellbeing. However, interestingly children with ADHD during lockdown, due to minimal exposure to the school-related stress, were less likely to be susceptible to anxiety [16]. Another component affecting the course of ADHD is the prenatal period, which is crucial in the development of that brain abnormality. For instance, maternal hypothyroidism in early pregnancy was associated with a bigger number of symptoms in children, independently of other factors, which indicates the importance of environmental factors that have an impact on the development of ADHD.

ADHD has an early onset in life and can persist across the lifespan, with some differences among the patients. Among adults, we can distinguish three subtypes: inattentive subtype, hyperactive/impulsive subtype and combined subtype while the hyperactive/impulsive and combined being the least and the most common subtype respectively. The hyperactive/impulsive subtype was more frequently observed in females, while the inattentive subtype was more frequent in males. In addition, this subtype showed worse quality of life and more often anxiety disorders [15]. This data is contradictory to previous study where no sex differences between subtypes were noted [18].

Symptoms in adults with ADHD may present differently than in children as hyperactivity, impulsivity and inattention has to become less visible in an adult world. Adults are more likely to describe their symptoms as inner restlessness, talkativeness or inability to sit still in meetings when it comes to hyperactivity. Impulsiveness may be expressed by difficulties in maintaining long-lasting relationships or keeping a job. Feeling of boredom, procrastination and inability to make decisions are just a few examples of inattentiveness. Generally speaking, adults with ADHD perform worse in life due to these reasons. For instance, they are less likely to finish college, experience difficulties in all employment- related aspects, and have poorer parent- child relationships. Moreover, individuals with ADHD are more of risk-takers compared to people without ADHD. They are more prone to drive dangerously, to be diagnosed with substance use disorder (SUD), to hurt themselves. Criminality is another phenomenon associated with ADHD. Studies estimated that around $40 \%$ of prison male inmates struggle with the disease [19].

\section{ADHD in women}

Different charts are used to determine the disease. It is often difficult since everyone is different and the rating scales which are used provide only a snapshot of a patient's life based on a strict symptoms list and when it comes to females, they are less likely to point out their symptoms than males do $[9,13]$. Most of the time they happen to be diagnosed later than males. It could be due to multiple reasons such as differences in predominant symptoms (women are more likely to internalize them than externalize), presence of depression or anxiety as comorbid psychiatric disorders as well as obsessive- compulsive disorder and also 
that criteria are made mainly for boys and not for girls [20]. They are more likely to present inattentiveness than males do [1]. One study from 2021 recruited 709 patients with tic disorders and other neurodevelopmental disorders such as ADHD and it showed that sex had significant impact on ADHD symptoms; women had more emotional problems compared to males [24]. It is known that boys are more likely to show risky behavior, however women with ADHD have an earlier onset of sexual activity, which can for some patients make them promiscuous. Moreover, inability to plan the future which can result in lack of constructive activities and occupations, lead them to the feeling of being overwhelmed and anxiety which push them to self-harm and substance use [21]. A comparative study done by Babinski et al. which compared 162,263 women and 225,705 men with ADHD showed that women were more frequently than men to have depression and the female sex was associated with suicidal ideation and a higher number of suicide attempts [22]. In a situation when some disease occurs more or less frequently in women as compared to men, firstly the hormonal impact is investigated. It is known that estrogen and progesterone levels have various brain effects which can affect emotional behavior. Some menopausal women had reported symptoms which strongly resemble ADHD symptoms in adults [25]. Hence, it may indicate that hormone - related deficiency could play a role in differences among symptoms in women. Study conducted by Doranis et al. on 209 women aged 17-81 years with ADHD showed that the prevalence of hormone related mood disorders like premenstrual dysphoric disorder (PMDD), or episodes of postpartum depression symptoms (PPD) was higher in these women comparing to the general population. It was the first study to suggest that ADHD females suffer more from hormone related mood disorders [23]. Polycystic ovarian syndrome, an endocrine disorder which is described by hyperandrogenism is known to affect mental health of women which include ADHD [27]. When it comes to pharmacotherapy, women and men are not equally seen by physicians. Both hyperactivity/impulsivity were strong predictors of ADHD medication status in females compared to males, even if clinically diagnosed, they were prescribed medications to the same extent. This suggests that if females display weaker externalizing problems they are less likely to be prescribed medication compared to men which can get necessary drugs based on ADHD diagnostic status only [27].

\section{Conclusions}

Together, these findings support an assumption that there are gender differences in ADHD symptoms, which should be taken into account by physicians. Implications of being undiagnosed with ADHD for many years in women can contribute to higher risk of other mental illnesses such as depression, which are more likely to have it.

Therefore, it is crucial to put an emphasis on education about these differences, which can make it hard to properly diagnose and start the treatment as soon as possible in order to make patients' lives easier to handle on an everyday basis.

\section{References}

1. Rucklidge JJ. Gender differences in attention-deficit/hyperactivity disorder. Psychiatr Clin North Am. 2010 Jun;33(2):357-73. doi: 10.1016/j.psc.2010.01.006. PMID: 20385342.

2. Data and Statistics About ADHD | CDC. (2021). Retrieved 18 September 2021, from https://www.cdc.gov/ncbddd/adhd/data.html 
3. Lange KW, Reichl S, Lange KM, Tucha L, Tucha O. The history of attention deficit hyperactivity disorder. Atten Defic Hyperact Disord. 2010 Dec;2(4):241-55. doi: 10.1007/s12402-010-0045-8. Epub 2010 Nov 30. PMID: 21258430; PMCID: PMC3000907.

4. Attention-deficit/hyperactivity disorder (ADHD) in children - Symptoms and causes. (2021). Retrieved 18 September 2021, from https://www.mayoclinic.org/diseasesconditions/adhd/symptoms-causes/syc-20350889

5. Attention deficit hyperactivity disorder (ADHD) - Symptoms. (2021). Retrieved 18 September 2021, from https://www.nhs.uk/conditions/attention-deficit-hyperactivity-disorderadhd/symptoms/

6. Attention deficit hyperactivity disorder (ADHD) - Causes. (2021). Retrieved 19 September 2021, from https://www.nhs.uk/conditions/attention-deficit-hyperactivity-disorderadhd/causes/

7. Ge GM, Leung MTY, Man KKC, Leung WC, Ip P, Li GHY, Wong ICK, Kung AWC, Cheung CL. Maternal Thyroid Dysfunction During Pregnancy and the Risk of Adverse Outcomes in the Offspring: A Systematic Review and Meta-Analysis. J Clin Endocrinol Metab. 2020 Dec 1;105(12):dgaa555. doi: 10.1210/clinem/dgaa555. PMID: 32810262.

8. Modesto T, Tiemeier H, Peeters RP, Jaddoe VW, Hofman A, Verhulst FC, Ghassabian A. Maternal Mild Thyroid Hormone Insufficiency in Early Pregnancy and AttentionDeficit/Hyperactivity Disorder Symptoms in Children. JAMA Pediatr. 2015 Sep;169(9):83845. doi: 10.1001/jamapediatrics.2015.0498. PMID: 26146876.

9. Nussbaum NL. ADHD and female specific concerns: a review of the literature and clinical implications. J Atten Disord. 2012 Feb;16(2):87-100. doi: 10.1177/1087054711416909. Epub 2011 Oct 5. PMID: 21976033.

10. Kok FM, Groen Y, Fuermaier ABM, Tucha O. The female side of pharmacotherapy for ADHD-A systematic literature review. PLoS One. 2020 Sep 18;15(9):e0239257. doi: 10.1371/journal.pone.0239257. PMID: 32946507; PMCID: PMC7500607.

11. Attention deficit hyperactivity disorder (ADHD) - Diagnosis. (2021). Retrieved 19 September 2021, from https://www.nhs.uk/conditions/attention-deficit-hyperactivity-disorderadhd/diagnosis/

12. Klassen AF, Miller A, Fine S. Health-related quality of life in children and adolescents who have a diagnosis of attention-deficit/hyperactivity disorder. Pediatrics. 2004 Nov;114(5):e541-7. doi: 10.1542/peds.2004-0844. PMID: 15520087. Taylor A, Deb S, Unwin G. Scales for the identification of adults with attention deficit hyperactivity disorder (ADHD): a systematic review. Res Dev Disabil. 2011 May-Jun;32(3):924-38. doi: 10.1016/j.ridd.2010.12.036. Epub 2011 Feb 12. PMID: 21316190.

13. Konikowska K, Regulska-Ilow B, Rózańska D. The influence of components of diet on the symptoms of ADHD in children. Rocz Panstw Zakl Hig. 2012;63(2):127-34. PMID: 22928358.

14. Beyens I, Valkenburg PM, Piotrowski JT. Screen media use and ADHD-related behaviors: Four decades of research. Proc Natl Acad Sci U S A. 2018 Oct 2;115(40):98759881. doi: 10.1073/pnas.1611611114. PMID: 30275318; PMCID: PMC6176582.

15. Salvi V, Migliarese G, Venturi V, Rossi F, Torriero S, Viganò V, Cerveri G, Mencacci C. ADHD in adults: clinical subtypes and associated characteristics. Riv Psichiatr. 2019 MarApr;54(2):84-89. doi: 10.1708/3142.31249. PMID: 30985833..

16. Bobo E, Lin L, Acquaviva E, Caci H, Franc N, Gamon L, Picot MC, Pupier F, Speranza M, Falissard B, Purper-Ouakil D. Comment les enfants et adolescents avec le trouble déficit d'attention/hyperactivité (TDAH) vivent-ils le confinement durant la pandémie COVID-19 ? [How do children and adolescents with Attention Deficit Hyperactivity Disorder (ADHD) experience lockdown during the COVID-19 outbreak?]. Encephale. 2020 
Jun;46(3S):S85-S92. French. doi: 10.1016/j.encep.2020.05.011. Epub 2020 Jun 7. PMID: 32522407; PMCID: PMC7276130.

17. Martinat M, Rossitto M, Di Miceli M, Layé S. Perinatal Dietary Polyunsaturated Fatty Acids in Brain Development, Role in Neurodevelopmental Disorders. Nutrients. 2021 Apr 2;13(4):1185. doi: 10.3390/nu13041185. PMID: 33918517; PMCID: PMC8065891.

18. Grevet EH, Bau CH, Salgado CA, Fischer AG, Kalil K, Victor MM, Garcia CR, Sousa NO, Rohde LA, Belmonte-de-Abreu P. Lack of gender effects on subtype outcomes in adults with attention-deficit/hyperactivity disorder: support for the validity of subtypes. Eur Arch Psychiatry Clin Neurosci. 2006 Aug;256(5):311-9. doi: 10.1007/s00406-006-0639-5. Epub 2006 May 12. PMID: 16685602.

19. Zalsman G, Shilton T. Adult ADHD: A new disease? Int J Psychiatry Clin Pract. 2016;20(2):70-6. doi: 10.3109/13651501.2016.1149197. Epub 2016 Apr 7. PMID: 27052374.

20. Quinn PO, Madhoo M. A review of attention-deficit/hyperactivity disorder in women and girls: uncovering this hidden diagnosis. Prim Care Companion CNS Disord. 2014;16(3):PCC.13r01596. doi: 10.4088/PCC.13r01596. Epub 2014 Oct 13. PMID: 25317366 ; PMCID: PMC4195638.

21. Young S, Adamo N, Ásgeirsdóttir BB, Branney P, Beckett M, Colley W, Cubbin S, Deeley Q, Farrag E, Gudjonsson G, Hill P, Hollingdale J, Kilic O, Lloyd T, Mason P, Paliokosta E, Perecherla S, Sedgwick J, Skirrow C, Tierney K, van Rensburg K, Woodhouse E. Females with ADHD: An expert consensus statement taking a lifespan approach providing guidance for the identification and treatment of attention-deficit/ hyperactivity disorder in girls and women. BMC Psychiatry. 2020 Aug 12;20(1):404. doi: 10.1186/s12888-020-027079. PMID: 32787804; PMCID: PMC7422602.

22. Babinski DE, Neely KA, Ba DM, Liu G. Depression and Suicidal Behavior in Young Adult Men and Women With ADHD: Evidence From Claims Data. J Clin Psychiatry. 2020 Sep 22;81(6):19m13130. doi: 10.4088/JCP.19m13130. PMID: 32965804; PMCID: PMC7540206.

23. Dorani F, Bijlenga D, Beekman ATF, van Someren EJW, Kooij JJS. Prevalence of hormone-related mood disorder symptoms in women with ADHD. J Psychiatr Res. 2021 Jan;133:10-15. doi: 10.1016/j.jpsychires.2020.12.005. Epub 2020 Dec 3. PMID: 33302160.

24. Garcia-Delgar B, Servera M, Coffey BJ, Lázaro L, Openneer T, Benaroya-Milshtein N, Steinberg T, Hoekstra PJ, Dietrich A, Morer A; EMTICS collaborative group. Tic disorders in children and adolescents: does the clinical presentation differ in males and females? A report by the EMTICS group. Eur Child Adolesc Psychiatry. 2021 May 4. doi: 10.1007/s00787-021-01751-4. Epub ahead of print. PMID: 33944988.

25. Pines A. Midlife ADHD in women: any relevance to menopause? Climacteric. 2016 Oct;19(5):423-5. doi: 10.3109/13697137.2016.1152536. Epub 2016 Feb 25. PMID: 26914101. 26. Rodriguez-Paris D, Remlinger-Molenda A, Kurzawa R, Głowińska A, Spaczyński R, Rybakowski F, Pawełczyk L, Banaszewska B. Psychiatric disorders in women with polycystic ovary syndrome. Psychiatr Pol. 2019 Aug 31;53(4):955-966. English, Polish. doi: 10.12740/PP/OnlineFirst/93105. Epub 2019 Aug 31. PMID: 31760419.

27. Mowlem FD, Rosenqvist MA, Martin J, Lichtenstein P, Asherson P, Larsson H. Sex differences in predicting ADHD clinical diagnosis and pharmacological treatment. Eur Child Adolesc Psychiatry. 2019 Apr;28(4):481-489. doi: 10.1007/s00787-018-1211-3. Epub 2018 Aug 10. PMID: 30097723; PMCID: PMC6445815. 